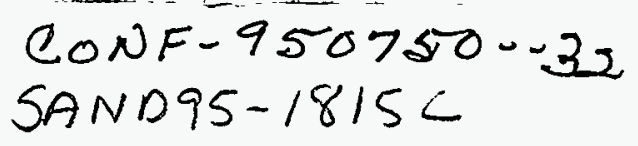

\title{
EXPLOSIVELY-DRIVEN MAGNETOHYDRODYNAMIC (MHD) GENERATOR STUDIES
}

\author{
Forrest J. Agee, Frederick M. Lehr \\ Phillips Laboratory \\ Kirtland AFB, NM 87117-5000 \\ Manny Vigil, Ronald Kaye \\ Sandia National Laboratories \\ Albuquerque, NM 87185-5800 \\ John Gaudet* , Donald Shiffler* \\ University of New Mexico \\ Albuquerque, NM 87106
}

\begin{abstract}
Plasma jet generators have been designed and tested which used an explosive driver and shocktube with a rectangular cross section that optimize the flow velocity and electrical conductivity. The latest in a series of designs has been tested using a reactive load to diagnose the electrical properties of the MHD generator/electromagnet combination. The results of these tests indicate that the plasma jet/MHD generator design does generate a flow velocity greater than $25 \mathrm{~km} / \mathrm{s}$ and produces several gigawatts of pulsed power in a very small package size. A larger, new generator design is also presented.
\end{abstract}

\section{INTRODUCTION}

There have been many studies and experiments conducted over the past several decades (Refs. 1, 2, and 3) on explosively-driven MHD generators (EDMHDG). A recent study of such devices (Ref. 4) demonstrated an explosive driver design that produced $1.8 \mathrm{GW}$ of pulsed power using argon gas at a velocity of $25 \mathrm{~km} / \mathrm{s}$ ivith a conductivity of $18,500 \mathrm{~S} / \mathrm{m}$. These early experiments were done using resistive loads. In the current effort, the latest available design was investigated for its electrical properties using a reactive (LC) load. Finally, a larger scale design was produced to reach higher voltages and output power levels.

\section{MHD GENERATOR DESIGN}

Figure 1 depicts the design of the EDMHDG used in the experiments reported here. Two pounds of explosive (COMP C4) are detonated from the left hand side using a exploding bridgewire (EBW) Reynolds Electronics RP-1 detonator. The explosive compresses via a shaped charge liner, heats, and ionizes the argon gas in the adjoining cavity initially at 200 psi pressure. The mylar diaphragm bursts with the force of the shock wave and allows the ionized argon to flow into the evacuated lexan shock tube, or MHD channel. An electromagnet is energized by the discharge of a capacitor bank so as to produce peak field during the main flow of Argon plasma in the channel. The subsequent $U \times B$ force (where $U$ is the flow velocity of the plasma and $B$ is the external magnetic field) on the free electrons in the plasma causes charge to be collected at the terminals to which the generator load is connected.

\footnotetext{
- Currently assigned to the Phillips Laboratory, PL/WSR, Kirtland AFB, NM 8711.
} 


\section{DISCLAIMER}

This report was prepared as an account of work sponsored by an agency of the United States Government. Neither the United States Government nor any agency thereof, nor any of their employees, make any warranty, express or implied, or assumes any legal liability or responsibility for the accuracy, completeness, or usefulness of any information, apparatus, product, or process disclosed, or represents that its use would not infringe privately owned rights. Reference herein to any specific commercial product, process, or service by trade name, trademark, manufacturer, or otherwise does not necessarily constitute or imply its endorsement, recommendation, or favoring by the United States Government or any agency thereof. The views and opinions of authors expressed herein do not necessarily state or reflect those of the United States Government or any agency thereof. 


\section{DISCLAIMER}

Portions of this document may be illegible in electronic image products. Images are produced from the best available original document. 


\section{MHD GENERATOR DESIGN EXPECTATIONS}

The open circuit voltage developed at the electrodes in the MHD channel is given by:

$$
\mathrm{V}_{o c}=\mathrm{UBd}
$$

where, $\mathrm{U}=$ flow speed in $\mathrm{m} / \mathrm{s}, \mathrm{B}=$ magnetic field strength in Tesla, and $\mathrm{d}=$ distance between the pickup electrodes in meters. The power delivered to the load for the MHD generator for the low magnetic Reynolds number case can be estimated for a rectangular channel from (Refs. 1, 4):

$$
\begin{aligned}
& P=K(1-K) \sigma(U B)^{2}(V o l), \text { for } \quad R_{m} \approx 1 \\
& P=\frac{2 B^{2} U d W}{\mu_{0}}, \text { for } \quad R_{m}>1
\end{aligned}
$$

where

$$
\begin{aligned}
& \mathrm{P}=\text { power in Watts } \\
& \mathrm{K}=\text { generator load parameter (dimensionless) } \\
& \sigma=\text { electrical conductivity of the plasma in Siemens } / \mathrm{m} \\
& \mu_{\mathrm{o}}=\text { permeability of free space }=4 \pi \times 10^{-7} \mathrm{H} / \mathrm{m} \\
& \mathrm{w}=\text { inside width of rectangular } \mathrm{MHD} \text { channel in meters } \\
& \mathrm{Vol}=\text { Volume of plasma slug in rectangular channel in } \mathrm{m}^{3}
\end{aligned}
$$

The generator load parameter is defined as the ratio of the generator output voltage under load to the open circuit generator voltage. Maximum power output is delivered to the load when $\mathrm{K}=0.5$. The magnetic Reynolds number, $R_{m}=\mu_{o} \sigma U d$, is a measure of the magnetic field trapped in the flow of the plasma. When $R_{m} \leq 1$, one can assume no magnetic field is trapped near the boundaries of the channel. Note that for the very high magnetic Reynolds number case, the power delivered by the generator is independent of the conductivity of the plasma and the length of the plasma slug. Also, the power only depends linearly on the flow velocity. As will be seen below, the $\mathrm{MHD}$ generators in these experiments have $\mathrm{R}_{\mathrm{m}}$ greater than 10 . For this type of generator, the Hall effect is important, the current in the plasma reaches a limit of $2 \mathrm{~B}_{0} w / \mu_{0}$, and the most important control parameters are the flow velocity and external magnetic field.

The EDMHD Generator design \#6 (Figure 1) configuration was modeled using the CTH hydrocode (Ref. 5) developed at Sandia National Laboratories. The CTH code predicted flow parameters at the center of the magnetic field produced by the electromagnet ( 9 inches from the shocktube entrance and diaphragm). The key results of CTH code calculations for design \#6 using 2 lbs of explosive, initial argon gas pressure of $200 \mathrm{psi}$, and a shocktube air pressure of 0.01 psi were: argon density $=44.5 \mathrm{~kg} / \mathrm{m}^{3}$, static pressure behind shock $=2.7 \mathrm{kbars}$, plasma temperature $=23,000 \mathrm{~K}$, plasma flow velocity $=25.5 \mathrm{~km} / \mathrm{s}$, and plasma flow arrival time $=57.7 \mu \mathrm{s}$.

In order to estimate the power, the electrical conductivity must be determined. For the case of a singly ionized gas, the Spitzer conductivity can be approximated by ${ }^{1}$ :

$$
\sigma=\frac{0.943 \sqrt{\frac{\pi}{8 m_{e}}}(k T)^{3 / 2}}{e^{2} \ln \left[\frac{3(k \mathrm{k})^{3 / 2}}{e^{3 \sqrt{8 \pi \mathrm{n}_{e}}}}\right]} .
$$

\footnotetext{
${ }^{1}$ See paper in Shuler (Ref. 8), "Ionization Behind Shock Waves," by J. D. Teare, p. 222.
} 
In this expression, $\mathrm{k}=$ Boltzmann constant $=1.38 \times 10^{-16} \mathrm{erg} / \mathrm{K}, \mathrm{T}=$ electron temperaturc in Kelvin, $\mathrm{m}_{\mathrm{e}}=$ mass of clcctron $=9.11 \times 10^{-28} \mathrm{~g}$, and $\mathrm{e}=$ electronic charge $=4.8 \times 10^{-10}$ esu.

The pressure behind the shock in the argon gas was calculated to be $2.7 \mathrm{kbars}$ or $2.7 \times 10^{8} \mathrm{~Pa}$, gas density of 44.5 $\mathrm{kg} / \mathrm{m}^{3}$, and the flow velocity is $25.5 \mathrm{~km} / \mathrm{s}$. The conductivity can now be estimated. The correct temperature to usc in eq. (3) is the electron temperature. With the argon gas speed (atom velocity) estimated at $25.5 \mathrm{~km} / \mathrm{s}$, a reasonable value for electron temperature ${ }^{2}$ is $14,000 \mathrm{~K}$ if a two percent degree of ionization is assumed. Under the above conditions, the electron density, $n_{\mathrm{e}}$, is $1.34 \times 10^{19} \mathrm{~cm}^{-3}$. Thus, the electrical conductivity of the argon gas flow is estimated to be $1.66 \times 10^{14} \mathrm{~s}^{-1}$, or 18,400 Siemens $/ \mathrm{m}$.

The experiment discussed here has been designed to include a magnetic field in the plasma flow channel, or shocktube, of about $9.4 \mathrm{~T}$ using two coils (one on each side of the shocktube) consisting of 13 turns of litz wire cable (Ref. 6). The energy for these coils is supplied by a $519 \mu \mathrm{F}$ capacitor bank charged to $10.43 \mathrm{kV}$ for $28.2 \mathrm{~kJ}$ of stored energy.

The expected results of this experiment can now be determined for the $0.5 \times 2$ inch cross section shocktube (electrodes are positioned across the 2 inch gap, thus $d=0.0508 \mathrm{~m}$ ). From eq. (1), the open circuit voltage generated by the EDMHDG is estimated to be $12.2 \mathrm{kV}$. The magnetic Reynolds number is 30 . Therefore, from eq. (2b), the maximum power delivered to the load is $2.3 \mathrm{GW}$. This, of course, implies a peak current, $I_{m}$, through the generator of $189 \mathrm{kA}$.

\section{TEST SETUP AND PROCEDURES}

The MHD generator depicted in Fig. 1 (design \#6) was tested using a capacitive load on two separate tests. The

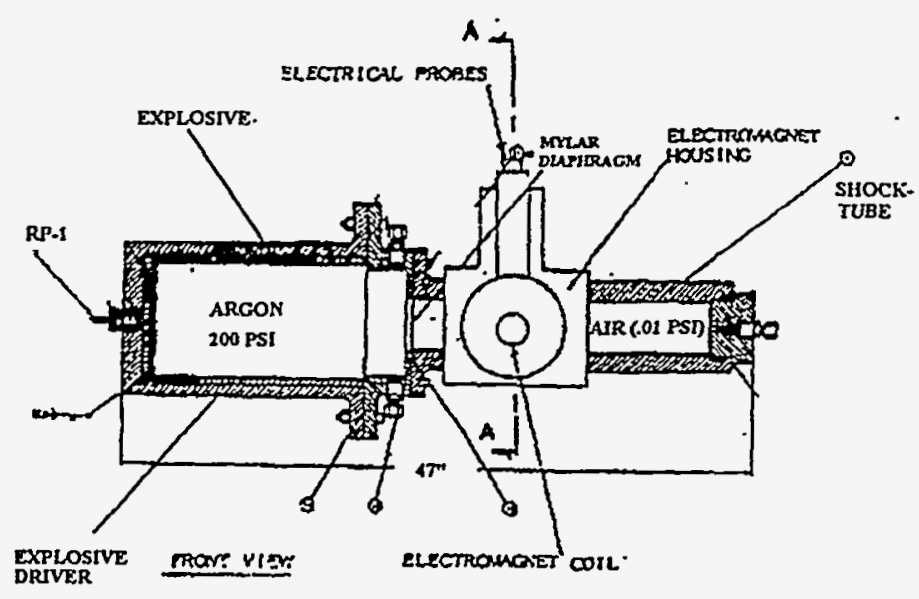

Figure 1. EDMFD Generator Design \#6 load was designed to match the impedance of the generator. An equivalent circuit model along with laboratory pulser testing of the load were used to determine the sensitivity of the experiment to the dynamic impedance of the generator. The main objective of these tests was to determine a more exact measurement of the dynamic impedance of design \#6. The load circuit was instrumented with voltage dividers and Rogowski coils. In addition, the MHDD generator was instrumented with sensors to measure the open circuit voltage, time of plasma arrival along the shocktube, electromagnetic coil performance, eddy current, etc. Table 1 provides a list of all these diagnostics and Ref. 7 explains their use and operation in more detail.

The procedures followed during the two tests were as follows: the capacitor bank was charged to a nominal 10 $\mathrm{kV}$. Once full charge was reached, a signal from the fire set triggered the bank to discharge. Then, a delay generator caused the detonator to fire $94 \mu$ s after the fire set signal. This delay was timed to allow for maximum plasma flow in the channel at peak magnetic field. Data was recorded from the probes for about $7 \mu$ sulse duration.

\footnotetext{
2In Shuler, "Ionization Behind Shock Waves," by J. D. Teare, p. 229 and the plot on p. 267.
} 


\section{EXPERIMENT RESULTS}

A circuit simulation using MICROCAP was conducted to determine the variation of load voltage and current as a function of generator total, dynamic impedance. The model constructed to simulate the tests is shown in fig. 2. The results of the circuit simulation are depicted in figs. 3 and 4.

Table I. EDMHD Generator Probes and Related Parameters

\begin{tabular}{|c|c|c|c|c|c|}
\hline No. & $\begin{array}{c}\text { I.D./Data } \\
\text { Channel }\end{array}$ & Type & $\begin{array}{l}\text { Location* } \\
\text { (in.) }\end{array}$ & $\begin{array}{c}\text { Related } \\
\text { Parameter }\end{array}$ & Comment \\
\hline 1 & OCVP \#1 & Voltage & 7.85 & $V_{\infty}, R, \sigma$ & Open circuit voltage - high \\
\hline 2 & OCVP \#1A & Voltage & 7.85 & $V_{a c,} R, \sigma$ & Open circuit voltage - low \\
\hline 3 & PIN SW \#5 & Arrival time & 30.75 & $\mathrm{U}$ & Ionization pin/plasma arrival \\
\hline 4 & BW current & Current & N/A & N/A & Detonator bridgewire current \\
\hline 5 & Eddy \#1 & Current & 20.75 & $\sigma$ & Eddy coil current - high \\
\hline$\frac{5}{6}$ & Eddy \#1A & Current & 20.75 & $\sigma$ & Eddy coil current - low \\
\hline 7 & Eddy di/dt \#I & Current/time & 20.75 & I dot & Differential current - high \\
\hline 8 & Eddy di/dt \#1A & Current/time & 20.75 & I dot & Differential current - low \\
\hline 9 & Volt. Div. \#IA & Voltage & 9.75 & $\mathrm{~V}$ & Load voltage - high \\
\hline 10 & Volt. Div. \#2A & Voltage & 9.75 & $\bar{V}$ & Load voltage - low \\
\hline 11 & Rog. \#1A & Current & 9.75 & $I$ & Load current - high \\
\hline 12 & Rog. \#2A & Current & 9.75 & $I$ & Load current - low \\
\hline 13 & Volt. Div. \#1 & Voltage & 9.75 & $\mathrm{~V}$ & Load voltage - high \\
\hline 14 & Volt. Div. \#2 & Voltage & 9.75 & $\mathrm{~V}$ & Load voltage - low \\
\hline 15 & Rog. \#1 & Current & 9.75 & $\mathrm{I}$ & Load current - high \\
\hline 16 & Rog. \#2 & Current & 9.75 & $\mathrm{I}$ & Load current - low \\
\hline 17 & PIN SW \#1 & Arrival time & 1.75 & $\mathrm{U}$ & Ionization pin/plasma arrival \\
\hline 18 & PIN SW \#2 & Arrival time & 4.00 & $\mathrm{U}$ & Ionization pin/plasma arrival \\
\hline 19 & PIN SW \#3 & Arrival time & 22.75 & $\mathrm{U}$ & Ionization pin/plasma arrival \\
\hline 20 & PIN SW \#4 & Arrival time & 26.75 & $\mathrm{U}$ & Ionization pin/plasma arrival \\
\hline 21 & EM Coil Rog. & Current & N/A & $B$ & EM coil current \\
\hline 22 & $\begin{array}{l}\text { EM Coil Volt. } \\
\text { Divider }\end{array}$ & Voltage & N/A & B & EM coil voltage \\
\hline
\end{tabular}

*Measured from shocktube entrance

The simulation results indicate that the designed load provides ample sensitivity to measure the impedance of the generator from $10 \mathrm{mohms}$ to over $100 \mathrm{mohms}$. Figure 5 contains the load voltage data for each experiment. Figure 6 shows the data from one of the open circuit voltage probes for both tests. As can be seen from the data, the peak voltages measured were considerably higher than the simple estimates discussed earlier. For example, the open circuit voltage for both shots exceeded $20 \mathrm{kV}$ and reached over $30 \mathrm{kV}$ for Test \#1. Assuming a simple matched load, the expected voltages on the load would be one half the open circuit voltage. Figure 5 shows a peak voltage that does approach $15 \mathrm{kV}$ but does not quite reach it. In analyzing the waveform for the load data on the first test, the best match that could be made to the simulation curves indicates a generator impedance of 130 mohms. In addition, the PIN switch data for both tests suggests a particle velocity of $20 \mathrm{~km} / \mathrm{s}$ which is 20 percent lower than the CTH calculated value. The peak power delivered was $1.8 \mathrm{GW}, 22$ percent less than predicted.

It should be noted that electrical breakdown probably occurred on both tests before a full pulse of energy was delivered. The breakdown is clearly evident on the second test and occurred before the peak voltage was reached. The data from load on the first test also shows evidence of electrical breakdown at, or just following, the peak signal. It is believed that a voltage probe cable breakdown occurred in the second instance. The origin of the breakdown for the first test has not been definitely established. 
Cirouit Model for load testing

at SNL

Small generator design

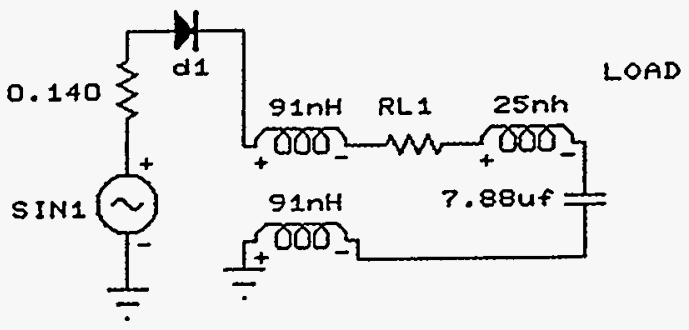

Figure 2. MICROCAP Circuit Simulation

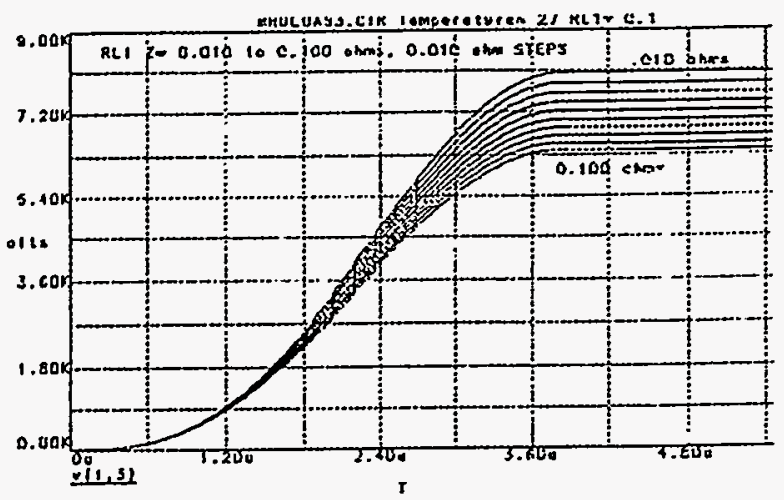

Figure 4. Circuit Simulation Results - Voltage vs. time with Load Impedance as Free Parameter

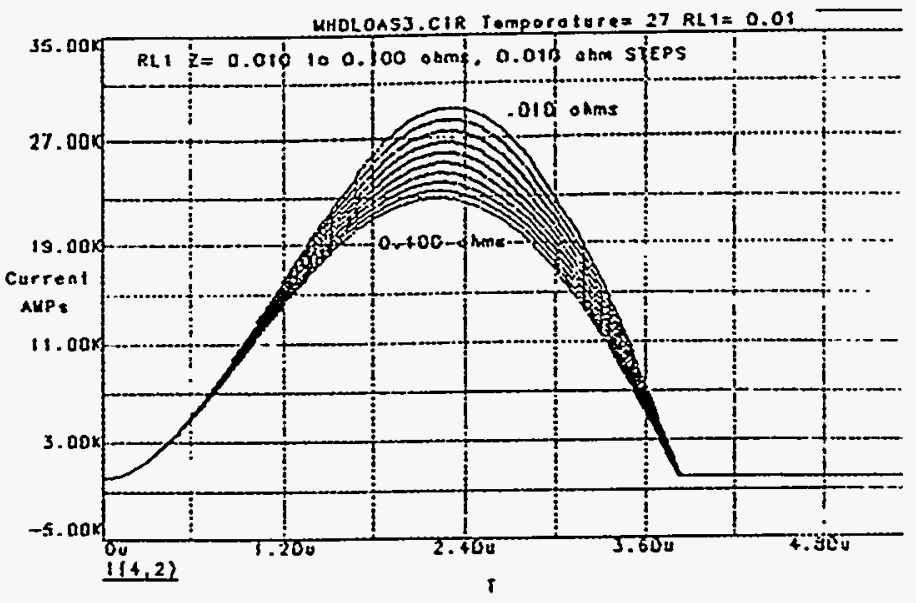

Figure 3. Circuit Simulation Results - Current vs. time with Load Impedance as Free Parameter

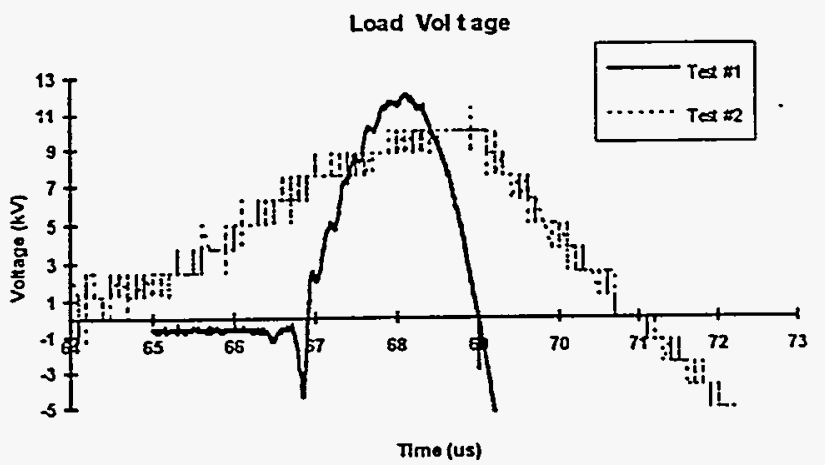

Figure 5. Load Voltage Test Results

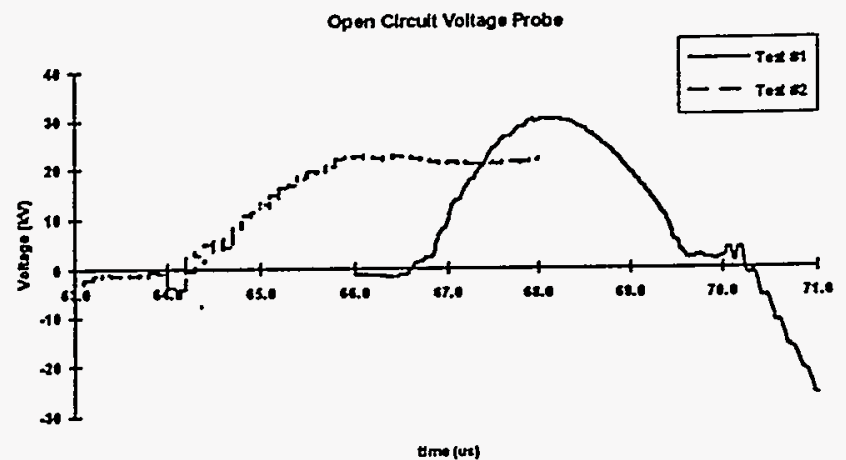

Figure 6. Open Circuit Voltage Test Results

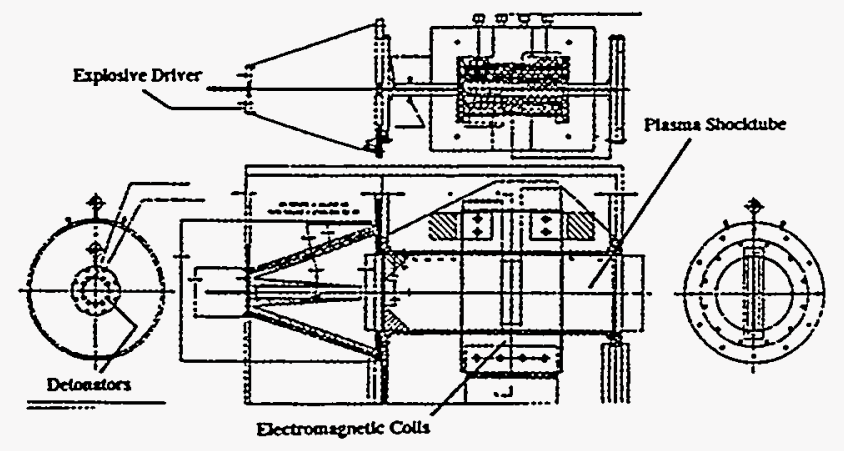

Figure 7. EDMHD Generator Design \#7 


\section{LARGER, SCALED EDMHD GENERATOR DESIGN}

A new design has been completed and hardware has been built and partially tested. The purpose of the new design is to determine if a much larger rectangular shocktube will allow higher voltages with similar currents (thus. at higher impedance) to be delivered to a capacitive load. To test this concept, an EDMHD Generator with a shocktube that is 12 in. $\times 0.5$ in. $\times 36$ in. long has been constructed. Figure 7 shows the basic design of this larger generator. A new electromagnet design, depicted in the figure as the U-shaped object, was required to provide a field of $12-15 \mathrm{~T}$ within the large volume of the shocktube. This coil, each half made of 4130 steel plates welded together to make 10 turns and connected so as to have additive fields between each half, has been tested up to energies of 1.5 MJ. The peak field along the axis of the channel was measured at $12.2 \mathrm{~T}$ for this case. The volume that this field is maintained at its peak is contained within the 3 inch by 13 inch oval slot with a spacing of 2.25 inches.

The following performance estimates are determined from eqs. (1) - (3) and the experience and modeling performed on the previous design and using: $U=25.5 \mathrm{~km} / \mathrm{s}$, electron temperature $=14,000 \mathrm{~K}, \sigma=18,400$ Siemens $/ \mathrm{m}$, Then, $V_{o c}=95 \mathrm{kV}, \mathrm{R}_{\mathrm{m}}=180, \mathrm{P}=23 \mathrm{GW}$, and $\mathrm{I}_{\mathrm{m}}=242 \mathrm{kA}$. Note that by scaling the shocktube by a factor of six in electrode separation increases the open circuit voltage by the same factor. Since the conductivities are about the same for both cases with a high magnetic Reynolds number, the power output is driven primarily by the size of the magnetic field. Since the power increases as the square of the magnetic field, a small increase in electromagnetic coil current will produce a significant amount of more power. This increase will have to be weighed against the problems associated with producing such high fields in a larger volume as the generator increases in size. This latest design of the EDMHD Generator has been built and will be tested experimentally to determine the effects of the many nonlinear properties associated with the MHD flow.

\section{REFERENCES}

1. Jones, Jr., M. S. and Blackman, V. H., "Parametric Studies of Explosive Driven MHD Power Generators," MHD Electrical Generation, Vol. 2, 1964, p. 803.

2. Jones, Jr., M. S., and McKinnon, Jr., C. N., "Explosive Driven Linear MHD Generators," Conference on Megagauss Magnetic Field Generation by Explosives and Related Experiments, Knoepfel, H. and Herlack, F. (eds.), European Atomic Energy Community: Brussels, 1966, p. 349.

3. Sharma, S. P., Schmidt, H. J., et. al. "Feasibility of an Optically Pumped Iodine Excimer $342 \mathrm{~mm}$ Laser Using Explosive MIDD Generator Plasma," Megagauss Technology and Pulsed Power Applications, Fowler, C. M., Caird, R. S., and Erickson, D. J. (eds.), Plenum Press: New York, 1987, p. 757.

4. Vigil, M. G., Duggins, B. D., Explosively-Driven Magnetohydrodynamic Generator: Phase I, Sandia National Laboratories, SAND94-0045, Aug. 1994.

5. McGlaun, J. M., Thompson, et. al., A Brief Description of the Three-Dimensional Shock Wave Physics Code CTH, Sandia National Laboratories, SAND89-0607, 1990.

6. Kaye, R. J., Cnare, E. C., et. al., "Design and Performance of Sandia's Contactless Coilgun for $50 \mathrm{~mm}$ Projectiles," IEEE Trans. on Magnetics, 29 (1), pp. 691-695, Jan, 1993.

7. Vigil, M. G., Duggins, B. D., Diagnostics Instrumentation Systems Development: Explosively-Driven Magnetohydrodynamic Generator Project; Phase I, Sandia National Laboratories, SAND94-0046, February, 1994.

8. Shuler, K. E. and Fenn, J. B. (eds.), Ionization in High-Temperature Gases, Academic Press: New York, 1963. 